\title{
PERANCANGAN SISTEM RESERVASI TIKET PADA PT GOLDEN EAGLE INDONESIA
}

\author{
Lius Steven Sanjaya; Stephanie Surja \\ Information Systems Department, School of Information Systems, Binus University \\ Jl. K.H. Syahdan No. 9, Palmerah, Jakarta Barat 11480 \\ lsanjaya@binus.edu; surjastephanie@gmail.com
}

\begin{abstract}
This study aims to identify the organization needs of PT Golden Eagle Indonesia to control and manage the data and information of operational transaction. The result of analysis is used as a base for developing a new integrated system that can be the solution for company needs and to face the competition. The activity in analysis and design is focused in ticket reservation activities, as the main business of the company. These needs will be documented using unified modeling language. There is an expectation that this system will ease the company in doing their activity in ticket reservation. This system will also minimize the data lost and human error usually caused by manual process of transactional data storage.
\end{abstract}

Keywords: analysis and design, information system, ticket reservation

\begin{abstract}
ABSTRAK
Analisis dan perancangan sistem informasi di PT Golden Eagle Indonesia bertujuan untuk mengidentifikasi kebutuhan perusahaan dalam pengelolaan data dan informasi transaksi operasional bisnisnya. Selanjutnya akan dibangun sebuah sistem terintegrasi yang dapat menjawab kebutuhan perusahaan dalam menjalankan operasional bisnisnya dan menghadapi persaingan dari kompetitor. Kegiatan analisis dan perancangan ini berfokus pada kegiatan reservasi tiket dari pemesanan hingga proses konfirmasi, yang merupakan main bisnis dari perusahaan. Hasil analisis terhadap kebutuhan-kebutuhan perusahaan akan didokumentasikan dengan menggunakan unified modeling language. Sistem informasi ini diharapkan mampu mempermudah kegiatan reservasi tiket di dalam perusahaan, di samping juga meminimalisasi kehilangan atau kesalahan data yang sering terjadi sebagai akibat dari penyimpanan data transaksi yang dilakukan secara manual dan tidak terorganisasi.
\end{abstract}

Kata kunci: analisis dan perancangan, sistem informasi, reservasi tiket 


\section{PENDAHULUAN}

Salah satu faktor kunci yang membantu perkembangan suatu perusahaan adalah sistem informasi yang mengintegarsikan operasional bisnis mereka dengan kegiatan bisnis mereka yang lain. Sistem informasi merupakan kumpulan dari hardware, dan software beserta sumber daya manusia yang akan mengolah data menggunakan hardware dan software tersebut (Gozali, Gunadhi, dan Kurniawati, 2012). Jika perusahaan telah menerapkan sebuah sistem informasi yang baik, kegiatan operasional perusahaan akan berjalan lancar dan terorganisasir dengan baik. Namun apabila sebuah perusahaan enggan mengikuti perkembangan teknologi serta sistem informasi, biasanya perusahaan tersebut akan mengalami hambatan dan kesulitan di dalam menghadapi persaingan dikarenakan sulitnya proses pengambilan, pencarian serta pengolahan data yang seharusnya menjadi kunci di dalam strategi bisnis mereka.

Proses pengolahan informasi pada sistem reservasi pesawat terbang dengan memanfaatkan teknologi web menyebabkan web menjadi media informasi yang dinamis yang dapat memudahkan calon penumpang dalam pemesanan tiket pesawat terbang. (Honggowibowo, Sediartie, 2005).

Sistem reservasi pesawat terbang pada suatu perusahaan sangat diperlukan guna efisien dan efektifitas perusahaan tersebut. Dalam sistem reservasi pesawat terbang ini mencakup segala informasi mengenai jadwal penerbangan, pemesanan tiket pesawat terbang, data penumpang pesawat terbang,biaya tiket pesawat terbang, pembatalan keberangkatan, daftar penumpang dalam suatu pesawat, daninformasi-informasi lain (Honggowibowo, Sediartie, 2005).

PT Golden Eagle Indonesia dengan nama usaha "Golden Eagle Tours dan Travel” merupakan suatu perusahaan yang bergerak pada bidang biro perjalanan wisata. Perusahaan ini didirikan pada tahun 2008. Dengan dukungan dari Travel Consultant professional yang bekerja untuk Golden Eagle, mereka dapat memberikan servis terbaik untuk pelanggan mereka. PT Golden Eagle Indonesia masih menggunakan sistem manual dalam operasional, seperti pembuatan letter of guarantee, invoice dan voucher hotel masih menggunakan Ms Excel and Word. Di samping itu, terjadi juga redundancy pada input data karena database yang dimiliki tidaklah saling berhubungan, sehingga redudan dalam input dan banyak human error yang tidak terdeteksi yang mengakibatkan data menjadi tidak akurat.

Dengan keadaan yang masih penuh dengan proses bisnis yang manual di dalam perusahaan kami berusaha memberikan solusi dengan cara menganalisis proses bisnis berjalan di PT Golden Eagle Indonesia yang saat ini masih manual dan membuat usulan rancangan sistem informasinya agar dapat meningkatkan efektivitas, efisiensi, dan produktivitas kerja perusahaan.

\section{METODE}

Metode yang digunakan dalam penulisan makalah ini adalah survei, tinjauan pustaka, serta penganalisisan proses bisnis berjalan yang ada sekarang guna membangun sebuah sistem informasi pada PT Golden Eagle Indonesia.

Pertama kali yang dilakukan adalah proses analisis dengan melakukan survei atas proses bisnis manual yang sedang berjalan di perusahaan dan dari survey tersebut didapatkan kebutuhankebutuhan perusahaan yang perlu diaplikasikan di dalam sistem informasi yang nantinya akan dibangun. Dokumentasi dari hasil analisis menggunakan unified modeling language yang didasarkan pada unified process disciplines (Satzinger, 2005). 


\section{HASIL DAN PEMBAHASAN}

\section{Proses Bisnis Berjalan}

Order tiket dapat dilakukan melalui telephon maupun melalui customer secara walk-in. Customer walk-in/ personal dapat melakukan order tiket secara langsung. Sedangkan untuk customer corporate, mereka harus melakukan agreement terlebih dahulu untuk mendapatkan Credit agreement. Credit agreement dapat dibuat dengan mengisi form permohonan corporate yang akan diberikan pada saat request.

Setelah melakukan pendaftaran, reservasi tiket diawali dengan konfirmasi tujuan, tanggal keberangkatan, estimasi jam keberangkatan, dan airlines yang diinginkan. Staf akan langsung melakukan kofirmasi ke dalam system airline yang dipilih sebelumnya atau melakukan kontak langsung ke airlines agar proses konfirmasi availability seat dapat diberikan kepada customer. Jika seat yang diinginkan tidak tersedia, staf terkait akan memberikan alternatif lain kepada customer untuk menggunakan airline lain, memilih jam keberangkatan lain, memilih harga tiket airlines yang lebih murah, atau memilih tanggal penerbangan lain. Setelah seat dan harga yang yang diinginkan sesuai, staf akan menanyakan nama dan nomor telepon yang dapat dihubungi untuk melengkapi proses pemesanan tiket yang sedang dilakukan.

Setelah reservasi dibuat, time limit akan diberikan kepada customer yang didapatkan dari system airlines terkait dan tiket yang telah dipesan tersebut harus dilakukan proses konfirmasi kembali sebelum time limit yang telah ditentukan. Apabila proses konfirmasi tersebut melewati time limit, sistem secara otomatis akan menngupdate tiket tersebut menjadi availability seat kembali. Setelah proses konfirmasi selesai dilakukan, customer akan diberikan kode booking.

Setelah proses konfirmasi dari customer diterima, selanjutnya adalah proses issued. Namun sebelumnya staf terkait akan melakukan proses pengecekkan terlebih dahulu terhadap credit limit yang dimiliki oleh customer. Apabila credit limit sudah melewati batas yang sudah ditentukan, proses issued tersebut tidak dapat dilakukan. Apabila customer belum memiliki ikatan dengan airlines yang diinginkan, staf perusahaan akan membuatkan Letter of Guarantee (LoG) 2 rangkap sesuai dengan informasi tiket yang akan di-issued. LoG rangkap 1 akan diberikan kepada pihak airlines/ pihak terkait agar bisa dilakukan proses issued untuk tiket tersebut. LoG rangkap 2 akan diberikan kepada bagian keuangan agar dapat dilakukan pembayaran kepada pihak airlines/ pihak terkait sesuai dengan harga yang sudah disepakati sebelumnya. Apabila customer sudah memiliki ikatan dengan airlines tertentu, ada dua pilihan untuk proses issued yang dapat dilakukan oleh customer yaitu top up/ in advanced atau credit.

Setelah proses issued selesai maka tiket tersebut baru dapat dicetak agar dapat dikirimkan kepada customer. Bersamaan dengan tiket yang akan dikirimkan staf akan langsung membuat Invoice dua rangkap serta tanda terima sesuai dengan harga tiket yang telah diinfokan kepada customer. Invoice rangkap 1 akan dikirimkan beserta dengan tiket yang terlah dicetak kepada customer melalui kurir sesudah tiket dan invoice rangkap 1 diterima , customer harus menandatangani tanda terima yang dibuat sebelumnya. Invoice rangkap 2 akan dikirimkan kebagian keuangan dan disimpan sebagai Credit Invoice. Pada saat jatuh tempo penagihan untuk masing-masing customer, bagian keuangan akan melakukan penagihan terhadap customer yang masih memiliki tunggakan pembayaran untuk tiket yang telah di-isued. Jika customer belum membayar, fasilitas credit mereka akan di-lock dan tidak dapat melakukan order tiket hingga pembayaran selesai dibuat. Jika Customer langsung membayar invoice sebelum jatuh tempo, bagian keuangan akan menerima pembayaran dan mengupdate status tagihan menjadi Paid. 


\section{Permasalahan yang Dihadapi}

Dibawah ini adalah beberapa permasalahan yang dihadapi berdasarkan analisisdari sistem berjalan: (1) seluruh proses bisnis di PT Golden Eagle Indonesia masih dilakukan secara manual, dimulai dari input transaksi yang terjadi, penyimpanan data hingga pembuatan LoG, invoice serta tanda terima; (2) ketidakakuratan data yang ada dikarenakan terjadinya human error yang terjadi akibatnya input berulang kali untuk data yang sama oleh masing-masing divisi terkait; (3) waktu yang cukup lama dalam pembuatan LoG, invoice serta tanda terima karena untuk pencarian informasi yang dibutuhkan untuk membuat dokumen tersebut harus dilakukan secara manual akibat dari pencatatan yang masih manual.

\section{Usulan Pemecahan Masalah}

Untuk mempermudah serta mempercepat kinerja dari PT Golden Eagle Indonesia, Golden Eagle perlu membuat sebuah sistem informasi yang dapat membantu mereka dalam otomatisasi pembuatan Letter of Guarantee, Invoice dan Voucher Hotel. Dan untuk penyimpanan data yang efektif dan efisien, diperlukan analisis terhadap database mereka dengan mengikuti alur proses bisnis mereka, untuk menciptakan database yang tidak redundancy, dan lebih efektif.

Gambar 1 di bawah ini merupakan activity diagram untuk usulan proses bisnis yang baru. Gambar 2 dan Gambar 3 berturut-turut adalah use case diagram dan domain class diagram.

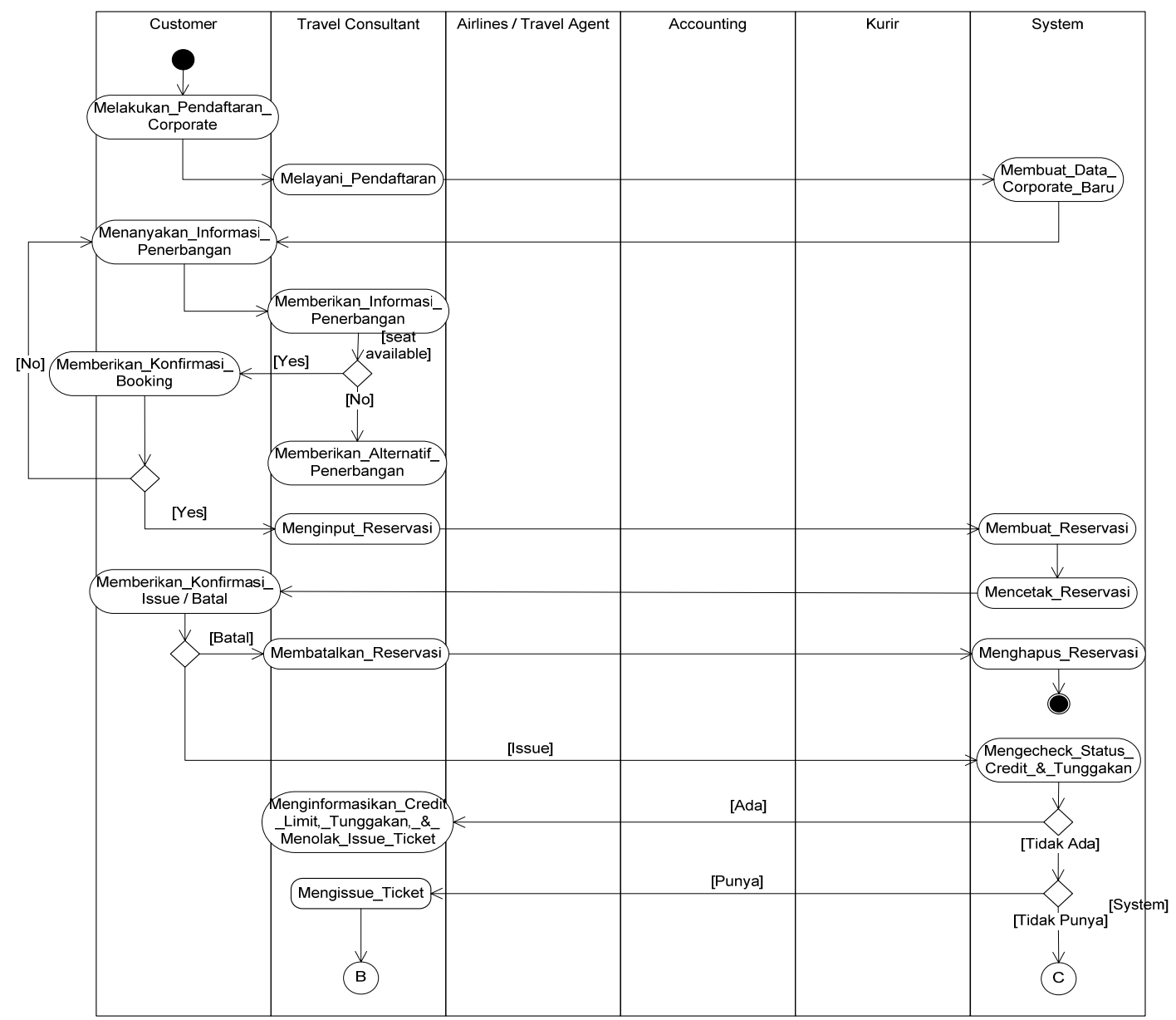




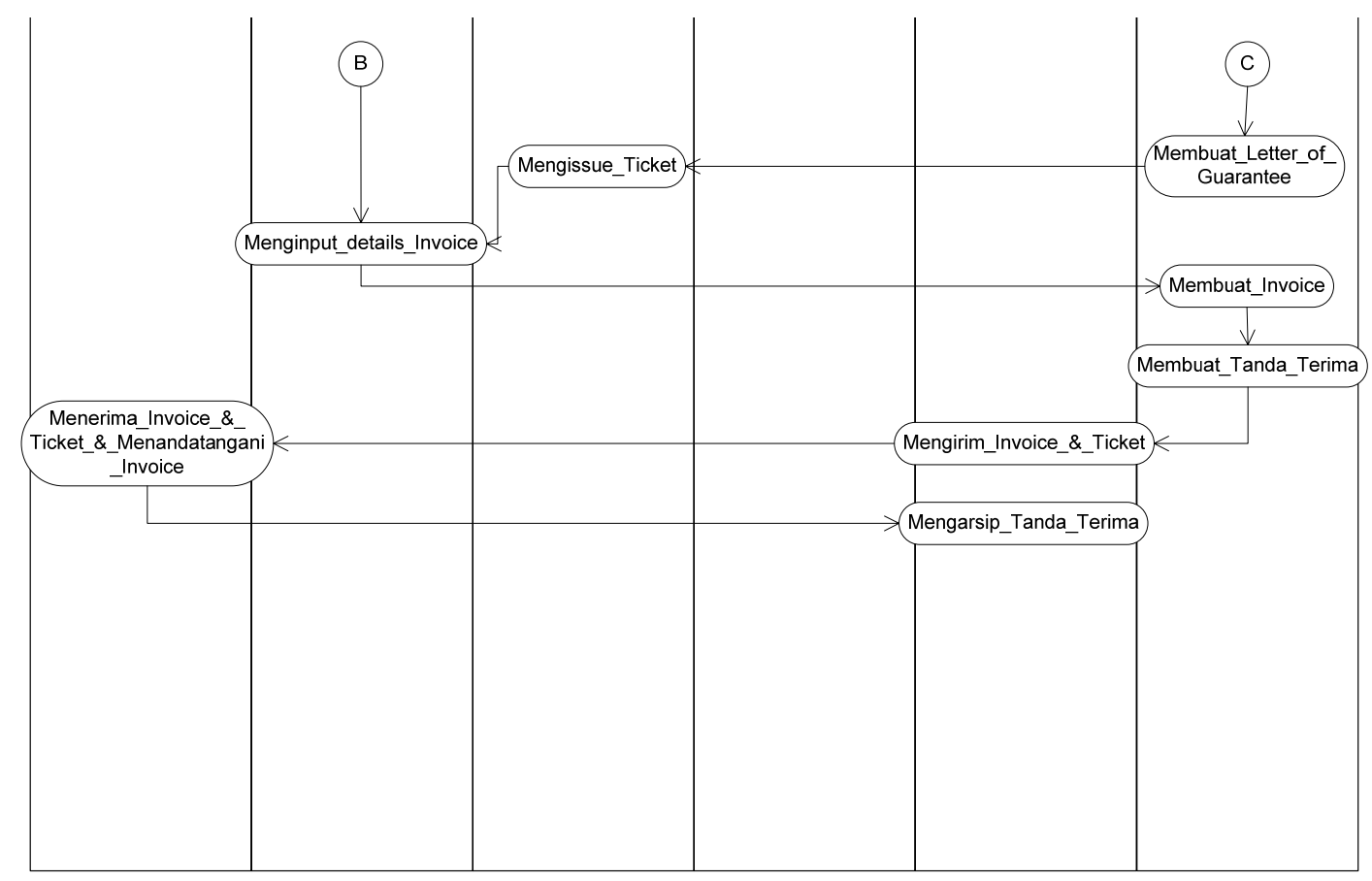

Gambar 1 Activity diagram untuk tata laksana sistem yang diusulkan

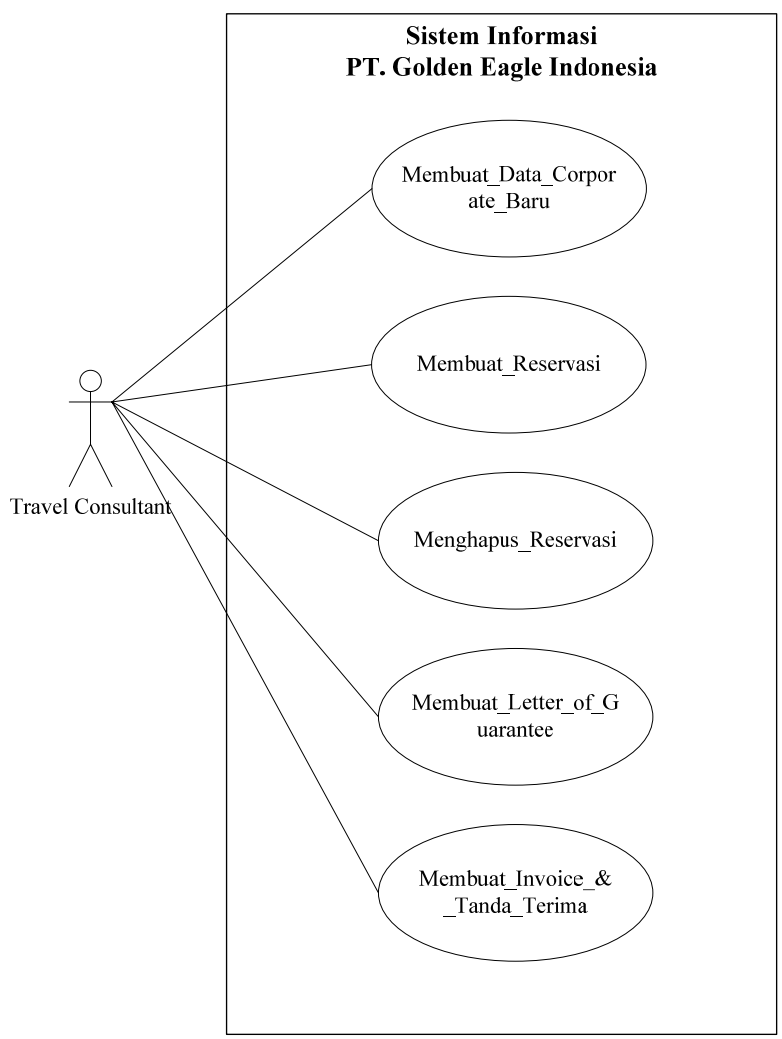

Gambar 2 Use case diagram 


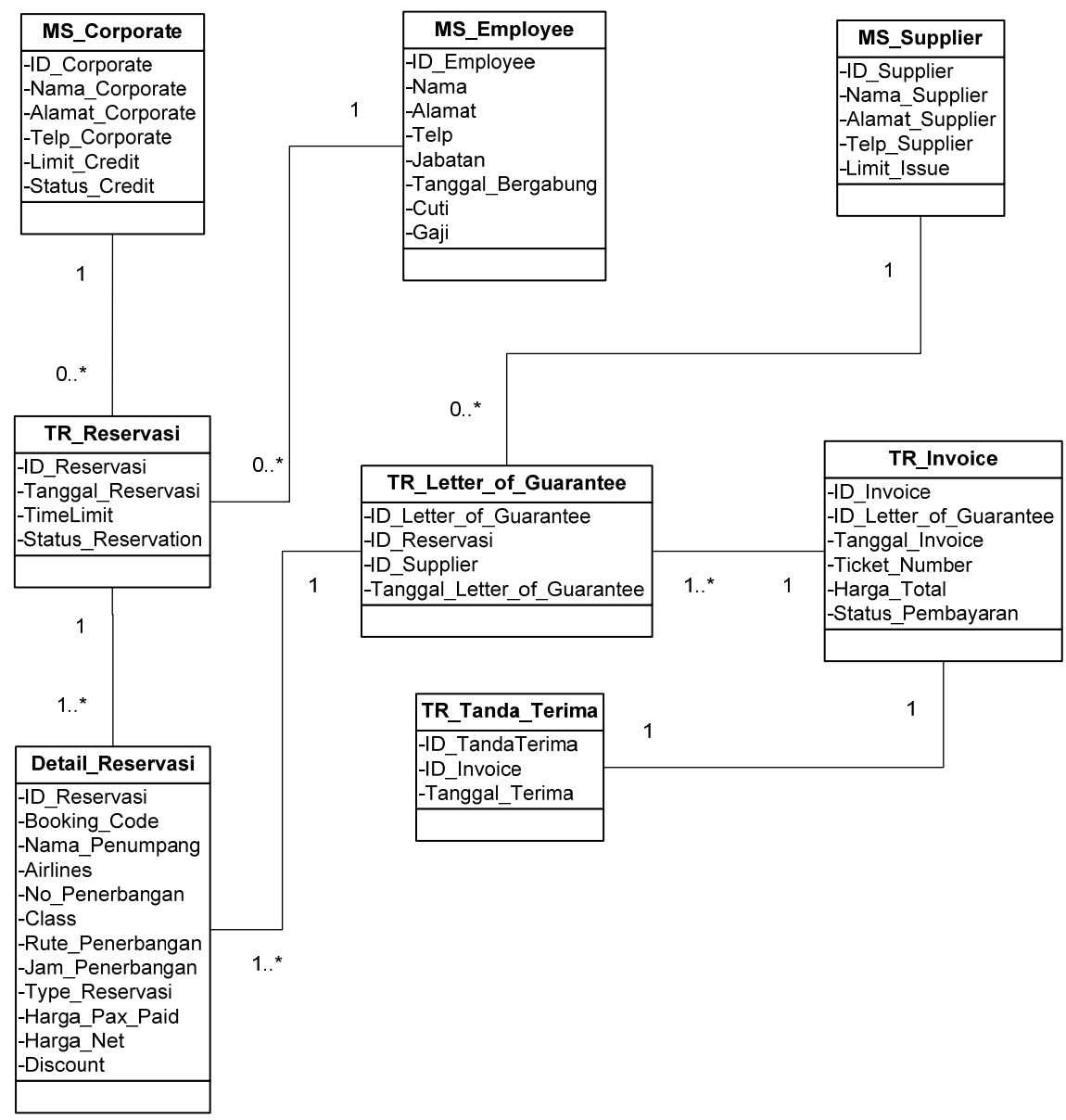

Gambar 3 Domain class diagram

Tabel 1 - 6 di bawah ini menguraikan use case description untuk setiap proses bisnis.

Tabel 1 Use Case Description: Membuat Data Corporate Baru

\begin{tabular}{cl}
\hline Use Case Name & \multicolumn{1}{c}{ Membuat Data Corporate Baru } \\
\hline Scenario & - \\
\hline Triggering Event & Pada saat customer corporate telah di-approve untuk membuat credit agreement \\
\hline Brief Description & $\begin{array}{l}\text { Customer corporate melakukan permohonan. Travel Consultant memberikan Form } \\
\text { Request Credit. Customer melengkapi Form Request. Customer membuat data } \\
\text { Corporate baru }\end{array}$ \\
\hline Actors & Travel Consultant \\
\hline Related Use Case & - \\
\hline Stakeholders & $\begin{array}{l}\text { Travel Consultant = Meng-input data Corporate baru } \\
\text { Direktur/ Manager = Memberikan persetujuan/ menolak corporate }\end{array}$ \\
\hline Preconditions & $\begin{array}{l}\text { (1). Customer melakukan dan melengkapi syarat pendaftaran; } \\
\text { (2). Direktur/ Ticketing manager telah menyetujui Credit agreement }\end{array}$ \\
\hline Postconditions & $\begin{array}{l}\text { (1). Data Corporate baru terbuat; } \\
\text { (2). Corporate dapat melakukan pemesanan secara credit }\end{array}$ \\
\hline Flow of Events & Actor \\
\hline
\end{tabular}




\begin{tabular}{|c|c|c|}
\hline & $\begin{array}{l}\text { (1). Calon Corporate mengajukan } \\
\text { permohonan agreement. } \\
\text { (2). Travel Consultant memberikan } \\
\text { Form permohonan corporate. } \\
\text { (3). Calon Corporate mengisi dan } \\
\text { melengkapi form permohonan dan } \\
\text { mengembalikan ke Travel } \\
\text { Consultant. } \\
\text { (4). Travel Consultant meminta } \\
\text { persetujuan kepada Direktur/ } \\
\text { Manager. } \\
\text { (5). Travel Consultant meng-input } \\
\text { details calon corporate baru. }\end{array}$ & $\begin{array}{l}\text { Menambahkan Corporate baru ke dalam } \\
\text { Database }\end{array}$ \\
\hline Exception Conditions & \multicolumn{2}{|c|}{$\begin{array}{l}\text { (1). Jika Data calon corporate tidak lengkap, Travel Consultant akan meminta } \\
\text { calon corporate untuk melengkapi data; } \\
\text { (2). Jika Permohonan tidak disetujui, status permohonan akan langsung ditolak } \\
\text { atau pending }\end{array}$} \\
\hline
\end{tabular}

Tabel 2 Use Case Description: Membuat Reservasi Non-Corporate via Telepon

\begin{tabular}{|c|c|c|}
\hline Use Case Name & \multicolumn{2}{|l|}{ Membuat Reservasi } \\
\hline Scenario & \multicolumn{2}{|l|}{ Customer By Phone (Non-Corporate) } \\
\hline Triggering Event & \multicolumn{2}{|l|}{ Customer memesan ticket } \\
\hline Brief Description & \multicolumn{2}{|c|}{$\begin{array}{l}\text { Customer melakukan booking, Travel Consultant menanyakan dan } \\
\text { menginformasikan details penerbangan, Customer memilih dan menentukan } \\
\text { penerbangan yg diinginkan, Travel Consultant melakukan booking dan meng-input } \\
\text { reservasi. }\end{array}$} \\
\hline Actors & \multicolumn{2}{|l|}{ Travel Consultant } \\
\hline Related Use Case & \multicolumn{2}{|l|}{-} \\
\hline Stakeholders & \multicolumn{2}{|c|}{ Travel Consultant $=$ Memberikan informasi dan alternative penerbangan } \\
\hline Preconditions & \multicolumn{2}{|c|}{ Details yang diberikan harus lengkap dan benar } \\
\hline Postconditions & \multicolumn{2}{|l|}{ Reservasi terbuat } \\
\hline \multirow[t]{2}{*}{ Flow of Events } & Actor & System \\
\hline & $\begin{array}{l}\text { (1). Customer menanyakan } \\
\text { penerbangan; } \\
\text { (2). TC menginformasikan detail } \\
\text { penerbangan; } \\
\text { (3). Customer memilih dan } \\
\text { menentukan penerbangan yang } \\
\text { diinginkan; } \\
\text { (4). TC melakukan booking; } \\
\text { (5). TC menambahkan details } \\
\text { reservasi; } \\
\text { (6). Melakukan pengulangan pada } \\
\text { langkah } 5 \text { hingga details reservasi } \\
\text { habis; } \\
\text { (7). TC menekan tombol submit; } \\
\text { (8). TC memberikan ID Reservasi } \\
\text { kepada Customer }\end{array}$ & $\begin{array}{l}\text { (1). Menambahkan detail reservasi; } \\
\text { (2). Menyelesaikan reservasi; } \\
\text { (3). Menghitung Total Amount }\end{array}$ \\
\hline Exception Conditions & \multicolumn{2}{|c|}{$\begin{array}{l}\text { (1). Jika Details penerbangan yang diinginkan tidak ada, Travel Consultant akan } \\
\text { mencarikan alternatif penerbangan; }\end{array}$} \\
\hline
\end{tabular}


(2). Jika Customer memberikan details yang tidak sesuai, Travel Consultant akan menanyakan details yang benar

Tabel 3 Use Case Description: Membuat Reservasi Non-Corporate Langsung (Walk-in)

\begin{tabular}{|c|c|c|}
\hline Use Case Name & \multicolumn{2}{|l|}{ Membuat Reservasi } \\
\hline Scenario & \multicolumn{2}{|l|}{ Customer Walk-in (Non-Corporate) } \\
\hline Triggering Event & \multicolumn{2}{|l|}{ Customer memesan ticket } \\
\hline Brief Description & \multicolumn{2}{|c|}{$\begin{array}{l}\text { Customer melakukan booking, Travel Consultant menanyakan dan } \\
\text { menginformasikan details penerbangan, Customer memilih dan menentukan } \\
\text { penerbangan yg diinginkan, Travel Consultant melakukan booking dan meng-input } \\
\text { reservasi. }\end{array}$} \\
\hline Actors & \multicolumn{2}{|l|}{ Travel Consultant } \\
\hline Related Use Case & \multicolumn{2}{|l|}{-} \\
\hline Stakeholders & \multicolumn{2}{|c|}{ Travel Consultant $=$ Memberikan informasi dan alternatif penerbangan } \\
\hline Preconditions & \multicolumn{2}{|c|}{ Details yang diberikan harus lengkap dan benar } \\
\hline Postconditions & \multicolumn{2}{|l|}{ Reservasi terbuat } \\
\hline \multirow[t]{2}{*}{ Flow of Events } & Actor & System \\
\hline & $\begin{array}{l}\text { (1). Customer menanyakan } \\
\text { penerbangan; } \\
\text { (2). TC menginformasikan details } \\
\text { penerbangan; } \\
\text { (3). Customer memilih dan } \\
\text { menentukan penerbangan yang } \\
\text { diinginkan; } \\
\text { (4). TC melakukan booking; } \\
\text { (5). TC menambahkan details } \\
\text { reservasi; } \\
\text { (6). Melakukan pengulangan pada } \\
\text { langkah } 5 \text { hingga details reservasi } \\
\text { habis; } \\
\text { (7). TC menekan tombol submit; } \\
\text { (8). TC mencetak reservasi untuk } \\
\text { customer }\end{array}$ & $\begin{array}{l}\text { (1). Menambahkan detail reservasi; } \\
\text { (2). Menyelesaikan reservasi; } \\
\text { (3). Menghitung total amount; } \\
\text { (4). Mencetak reservasi }\end{array}$ \\
\hline Exception Conditions & \multicolumn{2}{|c|}{$\begin{array}{l}\text { (1). Jika Details penerbangan yang diinginkan tidak ada, Travel Consultant akan } \\
\text { mencarikan alternative penerbangan; } \\
\text { (2). Jika Customer memberikan details yang tidak sesuai, Travel Consultant akan } \\
\text { menanyakan details yang benar; } \\
\text { (3). Jika Customer tidak meminta print out reservasi, tidak dilakukan print } \\
\text { reservasi }\end{array}$} \\
\hline
\end{tabular}

Tabel 4Use Case Description: Membuat Reservasi Corporate via Telepon

\begin{tabular}{cl}
\hline Use Case Name & Membuat Reservasi \\
\hline Scenario & Corporate By Phone \\
\hline Triggering Event & Customer memesan ticket \\
\hline Brief Description & $\begin{array}{l}\text { Customer melakukan booking, Travel Consultant menanyakan dan } \\
\text { menginformasikan details penerbangan, Customer memilih dan menentukan }\end{array}$ \\
\hline
\end{tabular}




\begin{tabular}{|c|c|}
\hline & $\begin{array}{l}\text { penerbangan yg diinginkan, Travel Consultant melakukan booking dan meng-input } \\
\text { reservasi. }\end{array}$ \\
\hline Actors & Travel Consultant \\
\hline Related Use Case & - \\
\hline Stakeholders & Travel Consultant = Memberikan informasi dan alternatif penerbangan \\
\hline Preconditions & $\begin{array}{l}\text { (1). Details yang diberikan harus lengkap dan benar } \\
\text { (2). Corporate memiliki credit agreement }\end{array}$ \\
\hline Postconditions & Reservasi terbuat \\
\hline \multirow[t]{2}{*}{ Flow of Events } & System \\
\hline & $\begin{array}{ll}\text { (1). Customer menanyakan penerbangan; } & \\
\text { (2). TC mengecheck status limit } & \\
\text { Corporate; } & \\
\text { (3). TC menginformasikan details } & \\
\text { penerbangan; } & \\
\text { (4). Customer memilih dan menentukan } & \text { (1). Mengecek status Corporate; } \\
\text { penerbangan yang diinginkan; } & \text { (2). Menambahkan detail reservasi; } \\
\text { (5). TC melakukan booking; } & \text { (3). Menyelesaikan reservasi; } \\
\text { (6). TC menambahkan details reservasi; } & \text { (4). Menghitung total amount } \\
\text { (7). Mengulang langkah } 5 \text { hingga details } & \\
\text { reservasi habis; } & \\
\text { (8). TC menekan tombol submit; } & \\
\text { (9). TC memberikan ID Reservasi kepada } & \\
\text { Customer } & \\
\end{array}$ \\
\hline Exception Conditions & $\begin{array}{l}\text { (1). Jika Status limit exceed, maka TC menolak melakukan reservasi dan meminta } \\
\text { membayar invoice yang sudah jatuh tempo; } \\
\text { (2). Jika Details penerbangan yang diinginkan tidak ada, Travel Consultant akan } \\
\text { mencarikan alternatif penerbangan; } \\
\text { (3). Jika Customer memberikan details yang tidak sesuai, Travel Consultant akan } \\
\text { menanyakan details yang benar }\end{array}$ \\
\hline
\end{tabular}

Tabel 5Use Case Description: Menghapus Reservasi

\begin{tabular}{|c|c|}
\hline Use Case Name & Menghapus Reservasi \\
\hline Scenario & - \\
\hline Triggering Event & Customer membatalkan perjalanan/ time limit exceed \\
\hline Brief Description & $\begin{array}{l}\text { TC meminta konfirmasi untuk tidak lanjut reservasi yang mendekati deadline, } \\
\text { Customer memberikan konfirmasi pembatalan reservasi }\end{array}$ \\
\hline Actors & Travel Consultant \\
\hline Related Use Case & - \\
\hline Stakeholders & Travel Consultant $=$ Menghapus Reservasi \\
\hline Preconditions & $\begin{array}{l}\text { (1). Time limit exceed/ time limit hampir tiba } \\
\text { (2). Reservasi ada }\end{array}$ \\
\hline Postconditions & Reservasi terhapus (void) \\
\hline \multirow[t]{2}{*}{ Flow of Events } & System \\
\hline & $\begin{array}{ll}\text { (1). TC mengecheck time limit } & \\
\text { reservasi; } & \text { (1). Mengecheck time limit reservasi; } \\
\text { (2). TC menghubungi Customer untuk } & \text { (2). Void Reservasi } \\
\text { meminta tindak lanjut reservasi; } & \end{array}$ \\
\hline
\end{tabular}


(3). Customer memberikan konfirmasi pembatalan;

(4). TC melakukan pembatalan reservasi

\begin{tabular}{cl}
\hline Exception Conditions & Jika time limit exceed, reservasi akan otomatis di void \\
\hline & Tabel 6 Use Case Description: Membuat Letter of Guarantee \\
\hline Use Case Name & Membuat Letter of Guarantee \\
\hline Scenario & - \\
\hline Triggering Event & Customer Memberikan konfirmasi untuk issue ticket \\
\hline Brief Description & $\begin{array}{l}\text { Customer memberikan konfirmasi untuk issue ticket, TC membuat Letter of } \\
\text { Guarantee, TC menyerahkan LG kepada kurir, Kurir memproses LG ke Airlines/ } \\
\text { Travel Agent }\end{array}$ \\
\hline Actors & Travel Consultant \\
\hline Related Use Case & $\begin{array}{l}\text { Travel Consultant = Membuat LG } \\
\text { Kurir Memproses LG ke Airlines/ Travel Agent }\end{array}$ \\
\hline Stakeholders & $\begin{array}{l}\text { (1). Reservasi Masih aktif } \\
\text { (2). Status limit customer masih aktif }\end{array}$ \\
\hline Preconditions & Letter of Guarantee terbuat \\
\hline Postconditions & Actor \\
\hline Flow of Events & System \\
\hline
\end{tabular}

(1). Customer memberikan konfirmasi issue reservasi;

(2). TC memastikan reservasi dengan membacakan kembali reservasi;

(3). Customer memberikan konfirmasi ke 2 ;

(1). Menampilkan reservasi;

(2). Create Letter of Guarantee;

4). TC membuat LoG;

(5). TC mencetak LoG;

(6). Kurir memproses LoG ke Airlines/ Travel Agent

Exception Conditions

(1). Jika reservasi ada kesalahan, TC akan melakukan pembenaran reservasi jika seat masih available;

(2). Jika kurir tidak ada, LoG bisa di Fax ke airlines/ travel agent untuk sementara

Gambar 4 - 8 merupakan sequence diagram yang dibuat. Selanjutnya Gambar 9 menampilkan state chart diagram.

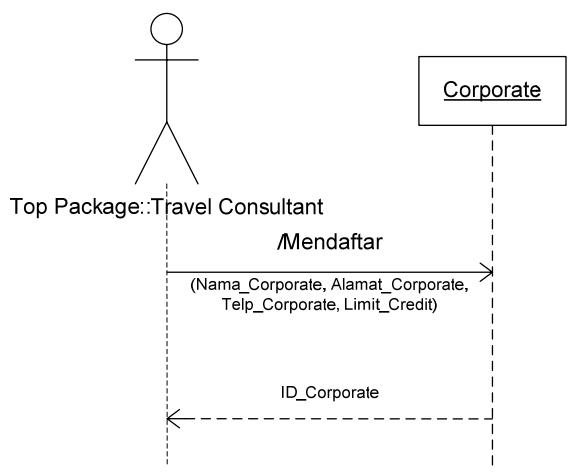

Gambar 4 SD: Data corporate baru 

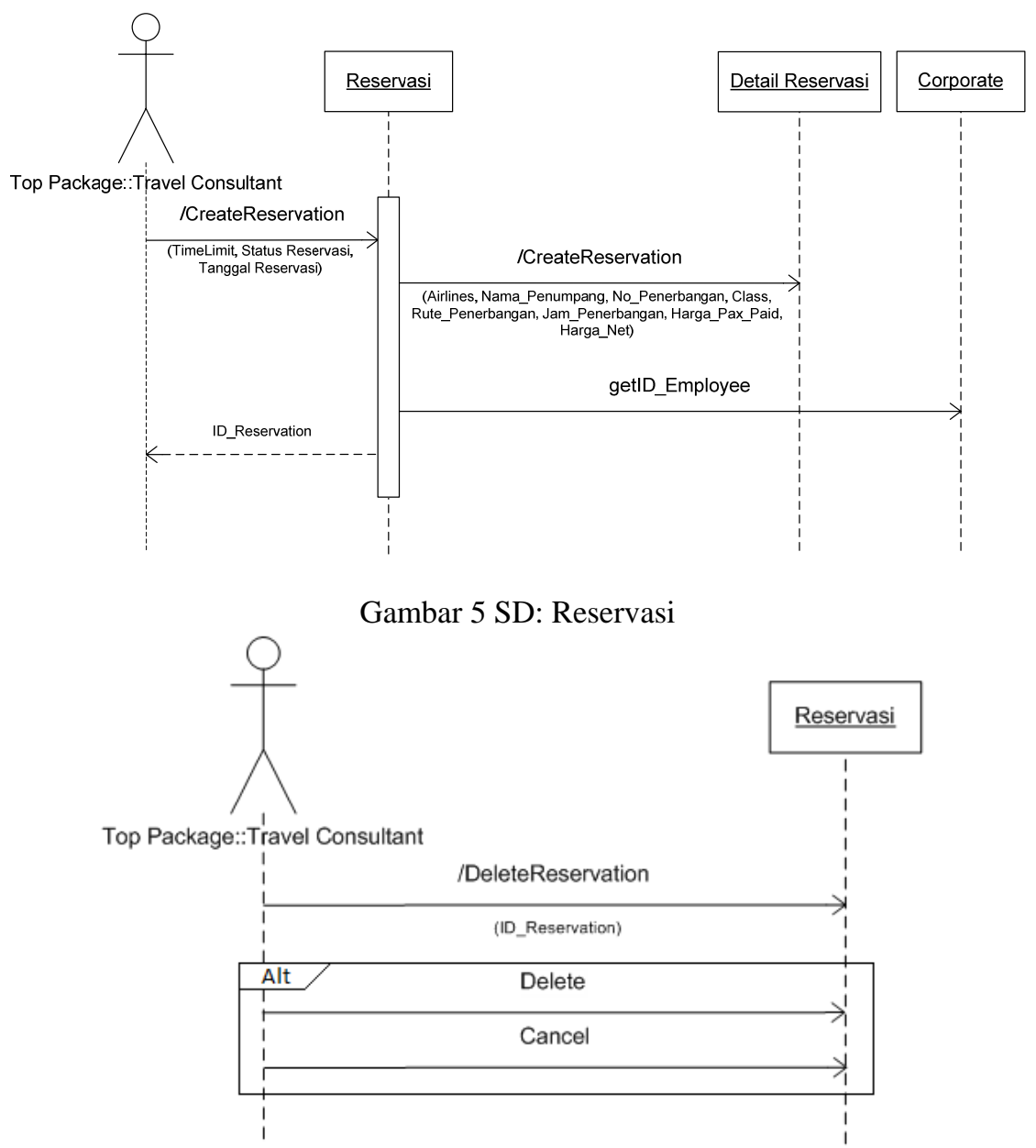

Gambar 6 SD: Hapus reservasi

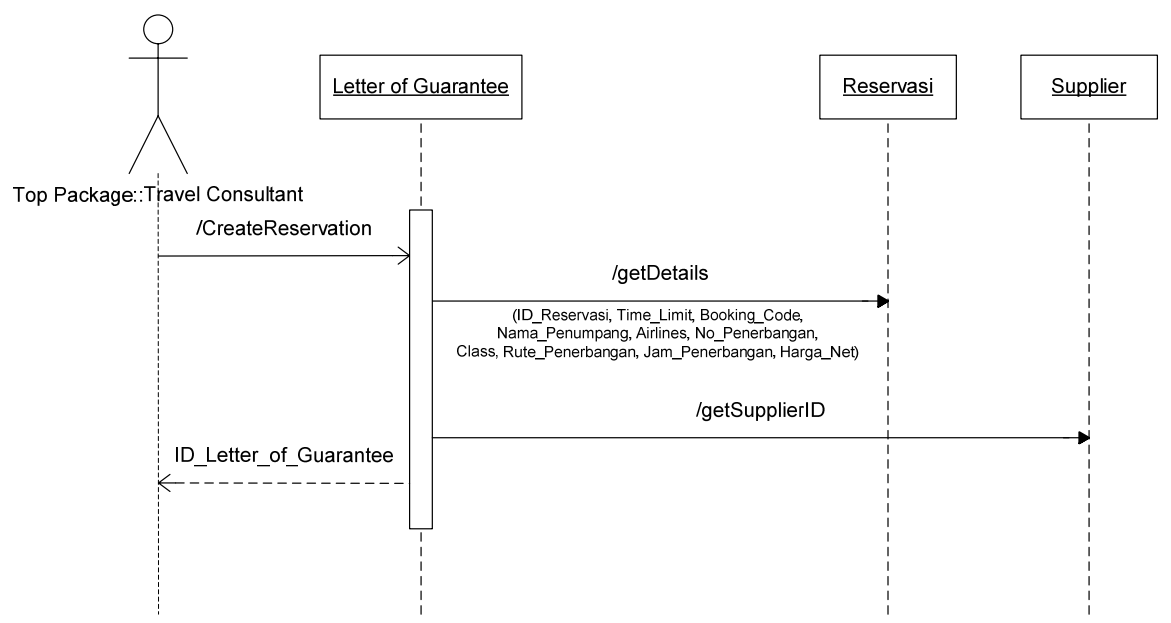

Gambar 7 SSD: Input Letter of Guarantee 


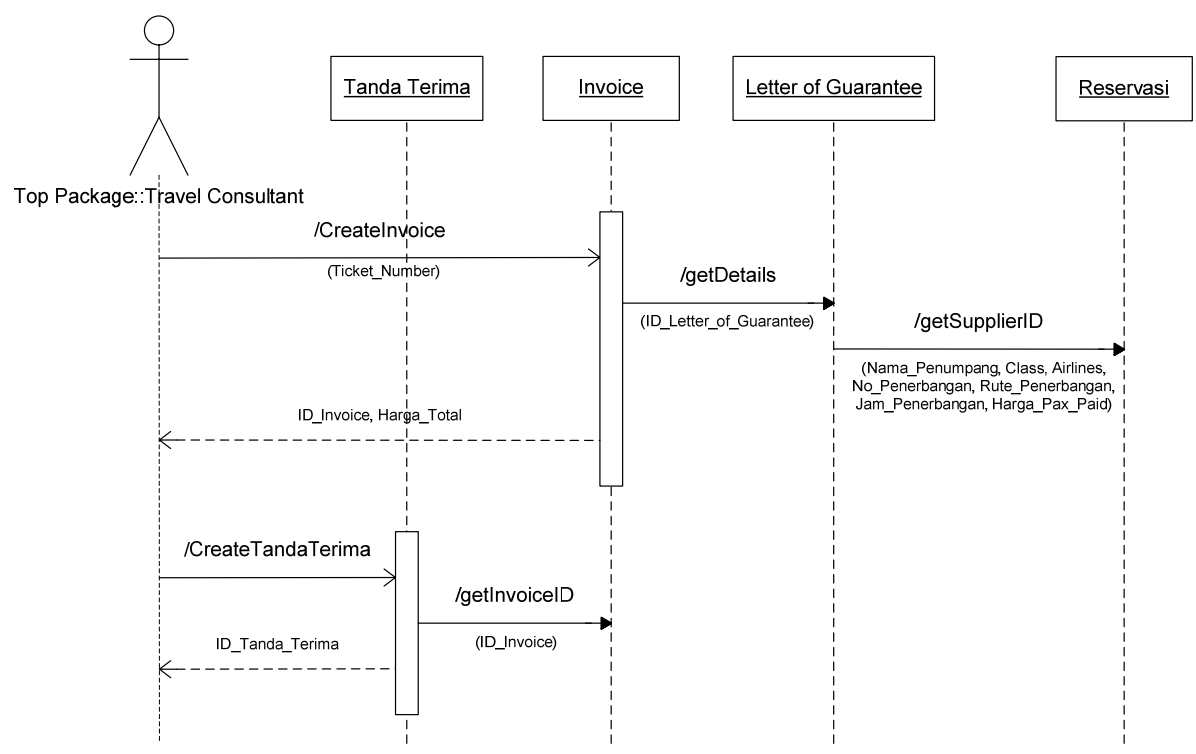

Gambar 8 SSD: Invoice dan Tanda Terima

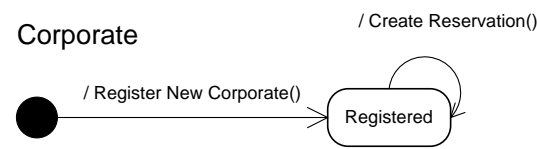

Letter of Guarantee

Reservasi

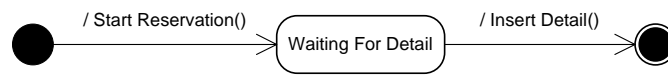

Invoice

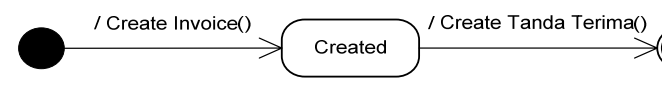

Detail Reservasi

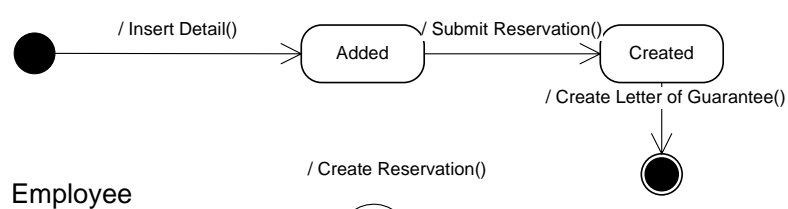

Tanda Terima

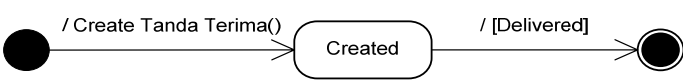

Employee
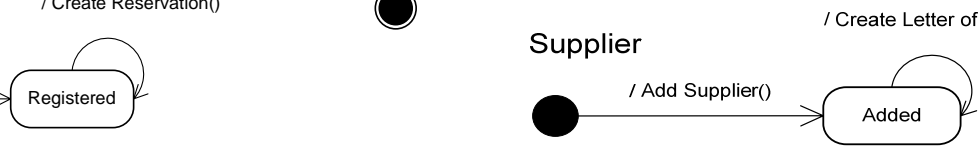

Gambar 9 State chart diagram

Gambar 10 - 12 merupakan rancangan layar yang telah didesain. 


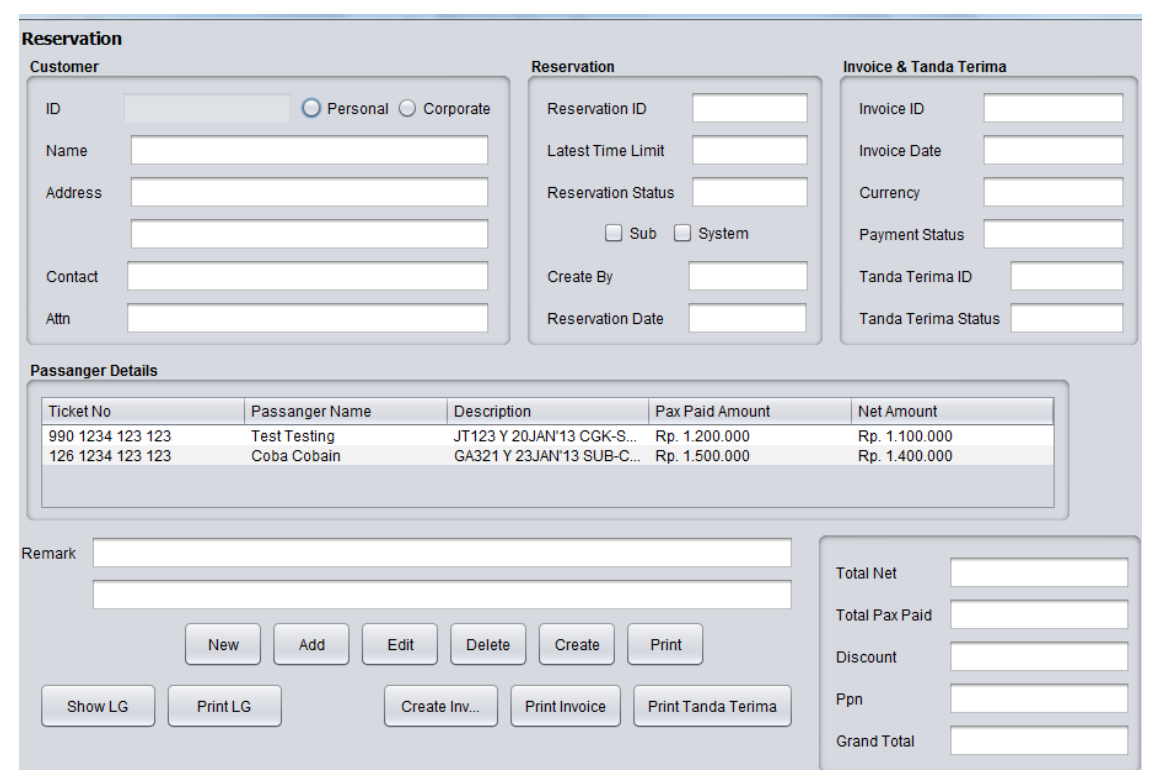

Gambar 10 Form reservasi

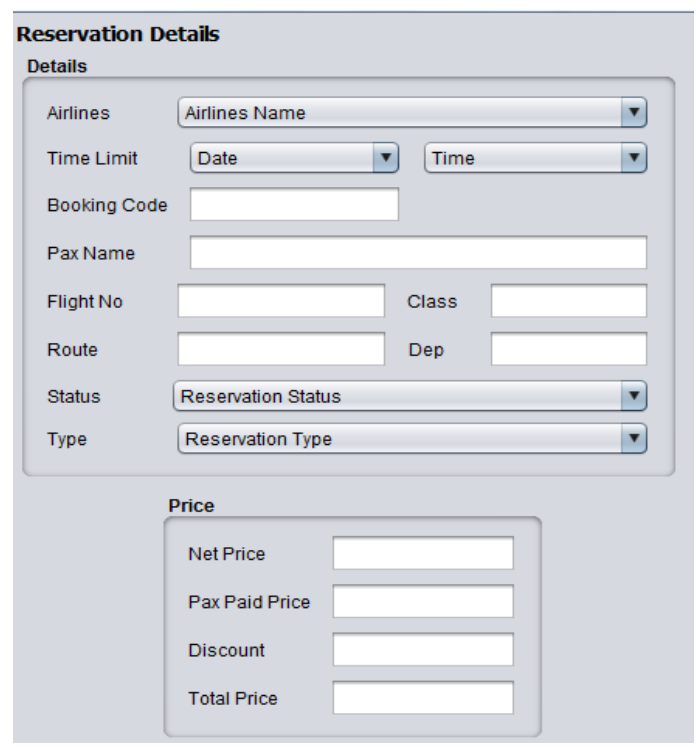

Gambar 11 Detail reservasi

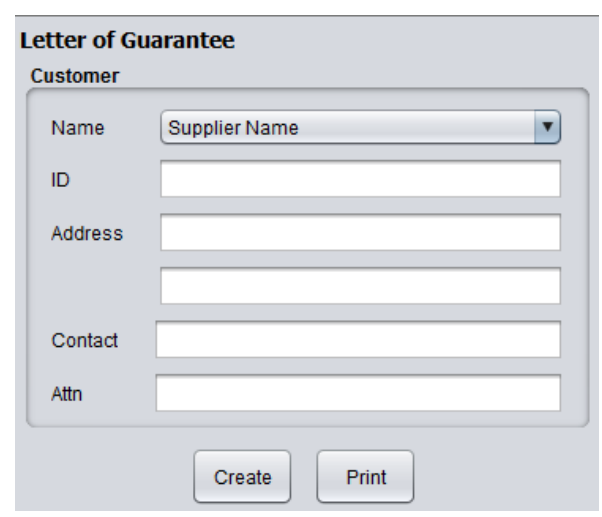

Gambar 12 Letter of Guarantee 


\section{PENUTUP}

Dari hasil analisis yang kami lakukan terhadap PT Golden Eagle Indonesia, didapatkan beberapa fitur yang perlu menjadi requirement utama dalam pembuatan sistem informasi yang sedang dirancang, yaitu: (1) seluruh proses bisnis di PT Golden Eagle Indonesia masih dilakukan secara manual, dimulai dari input transaksi yang terjadi, penyimpanan data hingga pembuatan LoG, invoice serta tanda terima; (2) ketidakakuratan data yang ada dikarenakan terjadinya human error yang terjadi akibatnya input berulang kali untuk data yang sama oleh masing-masing divisi terkait; (3) waktu yang cukup lama dalam pembuatan LoG, invoice serta tanda terima dikarenakan untuk pencarian informasi yang dibutuhkan untuk membuat dokumen tersebut harus dilakukan secara manual karena pencatatannya yang masih manual.

Saran yang dapat kami berikan antara lain: (1) perlunya diadakan sesi training dan sosialisasi terhadap seluruh karyawan terkait di dalam pemakaian system baru di dalam perusahaan; (2) sistem otomatisasi ini masih perlu dikembangkan sehingga terciptanya suatu integrasi dari seluruh proses bisnis sampai dengan proses operasional perusahaan; (3) masih diperlukan kontrol sistem, yaitu proses approval dan verifikasi sehingga data yang di-input ke dalam sistem pun tetap terkontrol dengan baik.

\section{DAFTAR PUSTAKA}

Gozali, L., Gunadhi, E., dan Kurniawati, R. (2012). Perancangan sistem informasi penjualan buku pada PD Restu Percetakan. Jurnal Algoritma, 9 (25), Sekolah Tinggi Teknologi Garut, ISSN: 2302-7339.

Honggowibowo, A. Sediartie, T. (2005). Sistem reservasi pesawat terbang berbasis web. Seminar Nasional Aplikasi Teknologi Informasi (SNATI 2005,) ISBN: 979-756-061-6.

Satzinger, John W.; Jackson, Robert B.; dan Burd, Stephen D. (2005). Object Oriented Analysis and Design with the Unified Process. Massachusetts: Course Technology. 